\title{
Adjuvant therapy for early endometrial cancer - who benefits the most from a radiation therapy?
}

\author{
Marcin Michalak®, Zaneta Warenczak-Florczak® \\ Agnieszka Staszewska-Nowak, Andrzej Roszak
}

Greater Poland Cancer Centre, Poznan, Poland

\begin{abstract}
Objectives: Since 1990s the number of patients diagnosed with endometrial cancer (EC) has doubled. The standard treatment method for treating early endometrial cancer is surgery. Some patients require a subsequent adjuvant therapy. In early endometrial cancers its application is limited to the populations with a high risk of recurrence.

The aim of this study was to assess the effectiveness of early endometrial cancer treatment based on an analysis of 5-year follow up of EC patients.

Material and methods: The analysis consisted in a retrospective non-randomized interventional study of patients treated for early endometrial cancer (FIGO stage IA, IB, II). Its end point was either local (small pelvis) or distant recurrence of the disease. Intervention involved an adjuvant treatment applied in selected patients according to the current guidelines for EC treatment. There was no randomization for adjuvant and non-adjuvant EC treatment. The study included a total of 419 patients treated for EC from 2010 to 2012.

Results: The analysis revealed that 108 patients (25.8\%) were diagnosed with the recurrent disease. Out of 112 patients treated for stage IA endometrial cancer 32 (28.6\%) experienced recurrence. Out of 216 patients at FIGO Stage IB, recurrence was diagnosed in $38(17.6 \%)$. In the group of 91 patients treated for FIGO stage II, EC the recurrence was diagnosed in $38(41.2 \%)$ cases. Conclusions: Early EC treatment results were unsatisfactory and should be improved. The best outcomes were achieved in patients with IA stage of EC who received a radiation therapy.

Key words: early endometrial cancer; adjuvant therapy; Treatment Effectiveness Assessment
\end{abstract}

Ginekologia Polska 2020; 91, 1: 6-12

\section{INTRODUCTION}

The endometrial cancer morbidity is on the increase, with a peak rate between 55 and 59 years of age. Since 1990s, the number of patients diagnosed with EC has doubled. In 1990 and 2010, 2540 and 5125 new EC cases were registered, respectively.

However, an increase of mortality rate is not as dynamic, with 763 and 1042 patient deaths due to EC in 1990 and 2010 , respectively. The difference between mortality and morbidity rate is due to early symptoms of the disease that enable early diagnosis and treatment [1-3].

The standard method for treating early endometrial cancer is surgery. Total hysterectomy with bilateral salpingo-oophorectomy, either open or laparoscopic is recommended.

In selected cases of EC (grade 3), pelvic and aortic lymph nodes should be removed. This procedure has a proven prognostic but not therapeutic value [4]. According to cur- rent guidelines, selected patients require subsequent adjuvant therapy. The aim of the adjuvant treatment (either radiation therapy or chemotherapy + radiation therapy) is to diminish the risk of local recurrence and/or distant metastases [5]. Recommended management of patients at the FIGO stage I is either follow-up or vaginal brachytherapy (VBT) alone or combined with external beam radiotherapy (EBRT). In our study, the patients at IA G1 were in follow up. Those at IA G2 stage were either in follow up or underwent vaginal brachytherapy. Qualification for the brachytherapy was based on pathological examination focused on specific risk factors for recurrence. Patients at IA G3 stage underwent complete radiation therapy (brachytherapy and external beam radiotherapy).

Patients at stage II were qualified for complete radiation therapy (VBT + EBRT). Selected patients at II G3 stage were qualified for complete radiation therapy and chemotherapy 
if defined risk factors were present in the pathological report (high risk patients).

As both radiotherapy and chemotherapy cause side effects, their application must be reasonable and based on firm evidence. Randomized clinical trials PORTEC- 1 and PORTEC-2 revealed that only high risk patients benefited from the adjuvant radiotherapy [6-8]. Recognized high risk factors included age (the older the worse), Grade 3 tumors, deep myometrial invasion, lymph nodes positive for metastases and lymphovascular space invasion [5, 9-11].

\section{Aim of the study}

The aim of this study was the Treatment Effectiveness Assessment (TEA) of early endometrial cancer based on the analysis of 5-year follow up of EC patients.

\section{MATERIAL AND METHODS}

The analysis was a retrospective interventional nonrandomized study of patients treated for early endometrial cancer (FIGO stage IA, IB and II). Its end point was either local (small pelvis) or distant recurrence of the disease. Intervention included an adjuvant treatment applied in selected patients according to the current guidelines for EC treatment. There was no randomization for adjuvant and non-adjuvant EC treatment. The study included a total of 419 patients treated for EC from 2010 to 2012.

All the patients were thoroughly analyzed for prognostic factors of population-based, clinical, and therapeutic nature and classified into two groups. The first group included the patients diagnosed with the recurrent disease, and the second those with no symptoms of the disease (controls).

Analysis of clinical data (medical history) revealed no significant differences between the patients. Detailed analysis is presented in Table 1.

All the patients underwent surgical treatment and qualification for subsequent adjuvant treatment was based on the final pathological examination. The patients received external beam radiation therapy (EBRT) with brachytherapy (VBT) or brachytherapy alone as a part of adjuvant treatment. EBRT was applied with Intense Modulate Radiation Therapy (IMRT) method in all cases. The range of physical dose of teleradiotherapy to the tumor and lymph node region was 45-50 Gy. Vaginal applications were given with High Dose Rate (HDR) brachytherapy. Dose distribution in applicators was $0.5 \mathrm{~cm}$ out of the first and half of the second segment of the vaginal cylinder. The range of physical dose of VBT was 18-37.5 Gy (Tab. 2).

The patients diagnosed with the recurrent disease received adequate treatment as per current radiotherapy and/or chemotherapy guidelines.

Time frame of the analysis was limited to the years 2010 - 2012 due to: a) modification of FIGO staging system (introduced in 2009) and b) 5-year follow up (completed in 2017).

\section{Statistical analysis}

Differences between the groups were analyzed using Statistic 6.0 (StatSoft, USA). t-Student test was used for comparison of means (data sets with parametric distribution). Mann-Whitney test was used for comparison of medians (data sets with non-parametric distribution). The chisquared test with Yates continuity correction was employed to determine the significance of differences between variable frequencies of the analyzed groups. Assumed level of significance was $p<0.05$.

\section{RESULTS}

The analysis showed that 108 (25.8\%) out of 419 patients were diagnosed with the recurrent disease. Among 112 patients treated for stage IA EC, 32 (28.6\%) experienced the recurrence. Out of 216 patients at FIGO Stage IB, $38(17.6 \%)$ were diagnosed with the recurrent disease. In the group of 91 patients treated for FIGO stage II EC 38 cases $(41.2 \%)$ of recurrence were diagnosed. Summarized data are presented in Table 3.

Some parameters describing treatment effectiveness based on the data outlined in Table 2 were analyzed and are discussed below.

Application of the adjutant treatment reduced relative risk of recurrence in patients at IA G1 stage of EC by over eight times (Tab. 4). Meanwhile, $88 \%$ of patients who received adjuvant treatment avoided recurrence at this stage of the disease. The adjuvant treatment reduced the relative risk of recurrence in patients at II G1 stage by only 2.9 times. This means that $66 \%$ of patients who received the adjuvant treatment avoided recurrence. The adjuvant treatment was also effective in patients at IB G2 stage, as 10 for every 12 patients who received it avoided recurrence. In other words, the adjuvant treatment at this stage of the disease reduced the relative risk of recurrence by approximately six times and $83 \%$ of the treated patients remained disease-free (Tab. 4).

Furthermore, the analysis of therapeutic methods (Tab. 2) showed that the addition of vaginal brachytherapy in FIGO IA patients significantly (8.3 times) reduced the risk of recurrence. More detailed data is presented in Table 5.

Median progression free survival (PFS) for all the patients included in the study was 28 months (2-125 months). A more detailed analysis revealed that in the group of patients at FIGO stages IA, IB and II the median PFS was 18 months (2-125), 28 months (3-120), and 32 months (2-125), respectively.

The analysis also included the localization of the recurrence. In the group of 108 recurring patients, in 44 cases 
Table 1. Clinical characteristics of Patients included into the study

\begin{tabular}{|c|c|c|c|c|}
\hline Stage & & Recurrent disease & Control & p \\
\hline \multirow{14}{*}{ FIGOIA } & Number of patients & 32 & 79 & - \\
\hline & Age [Years] & $62(52-82)$ & $62(45-82)$ & $0.618^{*}$ \\
\hline & BMI $\left[\mathrm{kg} / \mathrm{m}^{2}\right]$ & $31.2 \pm 7.3$ & $32.9 \pm 7.4$ & $0.272^{* *}$ \\
\hline & FMP [Years] & $14(10-17)$ & $14(10-18)$ & $0.165^{*}$ \\
\hline & Menopause [Years] & $49.5(43-57)$ & $50(41-50)$ & $0.120^{*}$ \\
\hline & Labour/Delivery & $2(0-2)$ & $2(0-6)$ & $0.816^{*}$ \\
\hline & Still birth & $2(6.25 \%)$ & $17(21.5 \%)$ & $0.098^{* * *}$ \\
\hline & Hypertension & $21(65.6 \%)$ & $49(62.0 \%)$ & $0.889^{* * *}$ \\
\hline & Diabetes mellitus & $9(28.1 \%)$ & $15(18.9 \%)$ & $0.421^{* * *}$ \\
\hline & Coronary artery disease & $6(18.7 \%)$ & $7(8.9 \%)$ & $0.253^{* * *}$ \\
\hline & Stroke & $1(3.1 \%)$ & $3(3.8 \%)$ & $0.697^{* * *}$ \\
\hline & Hypothyreosis & $4(12.5 \%)$ & $5(6.3 \%)$ & $0.487^{* * *}$ \\
\hline & Glaucoma & $1(3.1 \%)$ & $1(1.3 \%)$ & $0.904^{* * *}$ \\
\hline & Varicose veins & $3(9.4 \%)$ & $5(6.3 \%)$ & $0.875^{* * *}$ \\
\hline \multirow{14}{*}{ FIGOIB } & Number of patients & 38 & 178 & - \\
\hline & Age [Years] & $66(54-84)$ & $63(46-85)$ & $0.822^{*}$ \\
\hline & BMI $\left[\mathrm{kg} / \mathrm{m}^{2}\right]$ & $30.6 \pm 6.4$ & $31.9 \pm 5.6$ & $0.191^{* *}$ \\
\hline & FMP [Years] & $14(11-17)$ & $14(10-18)$ & $0.918^{*}$ \\
\hline & Menopause [Years] & $51(40-56)$ & $51(35-59)$ & $0.765^{*}$ \\
\hline & Labour/Delivery & $2(0-9)$ & $2(0-6)$ & $0.657^{*}$ \\
\hline & Still birth & $5(13.1 \%)$ & $39(21.9 \%)$ & $0.321^{* * *}$ \\
\hline & Hypertension & 22 (57.9\%) & $112(62.9 \%)$ & $0.692^{* * *}$ \\
\hline & Diabetes mellitus & $8(21.0 \%)$ & $42(23.6 \%)$ & $0.900^{* * *}$ \\
\hline & Coronary artery disease & $4(10.5 \%)$ & $18(10.1 \%)$ & $0.826^{* * *}$ \\
\hline & Stroke & $1(2.6 \%)$ & $4(2.2 \%)$ & $0.652^{* * *}$ \\
\hline & Hypothyreosis & $3(7.9 \%)$ & $11(6.2 \%)$ & $0.979^{* * *}$ \\
\hline & Glaucoma & $1(2.6 \%)$ & $7(18.4 \%)$ & $0.930^{* * *}$ \\
\hline & Varicose veins & $4(10.5 \%)$ & $11(6.2 \%)$ & $0.545^{* * *}$ \\
\hline \multirow{14}{*}{ FIGO II } & Number of patients & 38 & 51 & - \\
\hline & Age [Years] & $60(46-81)$ & $63(40-78)$ & $0.084^{*}$ \\
\hline & BMI $\left[\mathrm{kg} / \mathrm{m}^{2}\right]$ & $32.3 \pm 6.9$ & $31.7 \pm 6.3$ & $0.771^{* *}$ \\
\hline & FMP [Years] & $14(9-18)$ & $12(11-20)$ & $0.277^{* *}$ \\
\hline & Menopause [Years] & $50(46-54)$ & $51(45-58)$ & $0.307^{* *}$ \\
\hline & Labour/Delivery & $2(0-6)$ & $3(0-5)$ & $0.001^{* * *}$ \\
\hline & Still birth & $6(15.8 \%)$ & $9(17.6 \%)$ & $0.956^{* * *}$ \\
\hline & Hypertension & $16(42.1 \%)$ & $26(50.9 \%)$ & $0.538^{* * *}$ \\
\hline & Diabetes mellitus & $5(13.1 \%)$ & $11(21.6 \%)$ & $0.457^{* * *}$ \\
\hline & Coronary artery disease & $6(15.8 \%)$ & $7(13.7 \%)$ & $0.975^{* * *}$ \\
\hline & Stroke & $1(2.6 \%)$ & $1(1.9 \%)$ & $0.609^{* * *}$ \\
\hline & Hypothyreosis & $4(10.5 \%)$ & $6(11.8 \%)$ & $0.876^{* * *}$ \\
\hline & Glaucoma & $1(2.6 \%)$ & $2(3.9 \%)$ & $0.795^{* * *}$ \\
\hline & Varicose veins & 7 (18.4\%) & $2(3.9 \%)$ & $0.059^{* * *}$ \\
\hline
\end{tabular}

FMP — Firs Menstrual Period; BMI — Body Mass Index; ${ }^{*}$ Mann Whitney Test; ${ }^{*} \mathrm{t}$-Student test; ${ }^{* * *} \mathrm{X}^{2}$ Test with Yates Continuity Correction

$(41 \%)$ the recurrence was localized in small pelvis and in 64 cases (59\%) metastases were detected either in paraaortic lymph nodes or in other distant localizations. The patients at FIGO stage IA experienced recurrences in small pelvis in 
Table 2. Characteristics of Patients included into the study — focus on radiation therapy doses

\begin{tabular}{|c|c|c|c|c|}
\hline Stage & & Recurrent disease & Control & p \\
\hline \multirow{3}{*}{ FIGOIA } & Number of patients & 32 & 79 & - \\
\hline & Dose of Teletherapy [Gy] & $0(0-45)$ & $0(0-45)$ & $0.857^{* *}$ \\
\hline & Dose of Brachytherapy [Gy] & $0(0-30)$ & $28(0-37.5)$ & $0.00006^{* *}$ \\
\hline \multirow{3}{*}{ FIGOIB } & Number of patients & 38 & 178 & - \\
\hline & Dose of Teletherapy [Gy] & $45(0-45)$ & $45(0-50)$ & $0.563^{* *}$ \\
\hline & Dose of Brachytherapy [Gy] & $18(0-35)$ & $18(0-30)$ & $0.964^{* *}$ \\
\hline \multirow{3}{*}{ FIGO II } & Number of patients & 38 & 51 & - \\
\hline & Dose of Teletherapy [Gy] & $45(0-50)$ & $45(0-50)$ & $0.987^{* *}$ \\
\hline & Dose of Brachytherapy [Gy] & $18(0-20)$ & $18(18-30)$ & $0.415^{* *}$ \\
\hline
\end{tabular}

"Mann Whitney Test; ${ }^{* *} \mathrm{t}$-Student test; ${ }^{* * *} \mathrm{X}^{2}$ Test with Yates Continuity Correction

Table 3. General juxtaposition of the results - recurrence rate of early Endometrial Cancer

\begin{tabular}{|l|l|}
\hline Stage (FIGO) & Recurrence rate \\
\hline IA & $28.6 \%$ \\
\hline IB & $17.6 \%$ \\
\hline II & $41.2 \%$ \\
\hline
\end{tabular}

19 cases (59\%) and distant metastases in 13 cases (41\%). Among the patients at IB stage, 11 (29\%) recurrences were found in small pelvis and distant metastases were diagnosed in 27 cases (71\%). For the patients at stage II, these values were $14(37 \%)$ for small pelvis and 24 (63\%) for distant metastases.

Detailed analysis of metastasis localization revealed a correlation between the cancer grade and metastasis pattern. The more aggressive the cancer was (G1 -> G3), the more likely distant metastases were diagnosed. The patients with well differentiated tumors (G1) at FIGO stage IA were at risk of a local recurrence (vaginal vault), while those with poorly differentiated tumors were at risk of distant metastases. In the group of patients at FIGO stages IB and II, the recurrence pattern was different. All the patients were at risk of distant metastases, and the risk was increasing with the cancer grade (Tab. 6).

Contrary to the group who received the adjuvant treatment, the number of patients who did not receive it was relatively small and unequivocal conclusions could not be drawn (Tab. 7).

The analysis of population-based factors such as age, $\mathrm{BMI}$, age of the first menstrual period, number of births and miscarriages, or presence of concomitant diseases did not reveal any significant differences between controls and patients diagnosed with EC (Tab. 1).

\section{DISCUSSION}

Early endometrial cancer is considered a well differentiated malignant disease with relatively good prognosis that reflects low risk of either local recurrences or distant metastases. On the other hand, EC is a non-homogenous disease that comprises at least two types differing in histology, course of the disease, and treatment. Therefore, despite good prognosis, endometrial cancer patients still suffer from treatment failure and recurrences.

Table 4. Impact of adjuvant treatment on selected parameters

\begin{tabular}{|c|c|c|c|c|c|c|}
\hline Stage & Grade & $\mathbf{R R}$ & RRR & 1/RR & PF & NNT \\
\hline \multirow{3}{*}{ I A } & G1 & 0.12 & -0.88 & 8.30 & $88 \%$ & -2.22 \\
\hline & G2 & 0.31 & -0.69 & 3.27 & $69 \%$ & -2.52 \\
\hline & G3 & - & - & - & - & - \\
\hline \multirow{3}{*}{ I B } & G1 & 0.24 & -0.76 & 4.25 & $76 \%$ & -2.62 \\
\hline & G2 & 0.17 & -0.83 & 5.75 & $83 \%$ & -1.21 \\
\hline & G3 & - & - & - & - & - \\
\hline \multirow{3}{*}{ II } & G1 & 0.34 & -0.66 & 2.90 & $66 \%$ & -1.53 \\
\hline & G2 & - & - & - & - & - \\
\hline & G3 & - & - & - & - & - \\
\hline
\end{tabular}

RR — Relative Risk; RRR — Relative Risk Reduction; 1/RR — inverse Relative Risk; PF — Preventive Fraction; NNT — Number Needed to Treat 


\begin{tabular}{|c|c|c|c|}
\hline \multirow{2}{*}{ Stage } & \multirow{2}{*}{ Grade } & \multicolumn{2}{|c|}{ Median time to recurrence [months] } \\
\hline & & Adjuvant treatment & No Adjuvant treatment \\
\hline \multirow{3}{*}{ IA } & G1 & 11 & $29(3-125)$ \\
\hline & G2 & $14(2-57)$ & $13(6-46)$ \\
\hline & G3 & 4 & - \\
\hline \multirow{3}{*}{ IB } & G1 & $35(5-76)$ & - \\
\hline & G2 & $28(3-120)$ & 13 \\
\hline & G3 & $25(9-83)$ & - \\
\hline \multirow{3}{*}{ II } & G1 & $34(11-125)$ & $25(15-34)$ \\
\hline & G2 & $30(2-78)$ & - \\
\hline & G3 & $29(3-54)$ & - \\
\hline
\end{tabular}

Table 6. Metastases (localization and rate) in group of early EC patients. who received adequate adjuvant treatment

\begin{tabular}{|c|c|c|c|}
\hline Stage & Grade & Metastases & Rate $\%$ \\
\hline \multirow{3}{*}{ IA } & G1 & $\begin{array}{l}\text { Local (vaginal vault) } \\
\text { Distant }\end{array}$ & $\begin{array}{l}100.0 \\
0.0\end{array}$ \\
\hline & G2 & $\begin{array}{l}\text { Local (vaginal vault) } \\
\text { Distant }\end{array}$ & $\begin{array}{l}43.0 \\
47.0\end{array}$ \\
\hline & G3 & $\begin{array}{l}\text { Local (vaginal vault) } \\
\text { Distant }\end{array}$ & $\begin{array}{l}0.0 \\
100.0\end{array}$ \\
\hline \multirow{3}{*}{ IB } & G1 & $\begin{array}{l}\text { Local (vaginal vault) } \\
\text { Distant }\end{array}$ & $\begin{array}{l}33.3 \\
66.7\end{array}$ \\
\hline & G2 & $\begin{array}{l}\text { Local (vaginal vault) } \\
\text { Distant }\end{array}$ & $\begin{array}{l}30.0 \\
70.0\end{array}$ \\
\hline & G3 & $\begin{array}{l}\text { Local (vaginal vault) } \\
\text { Distant }\end{array}$ & $\begin{array}{l}12.5 \\
87.5\end{array}$ \\
\hline \multirow{3}{*}{ II } & G1 & $\begin{array}{l}\text { Local (vaginal vault) } \\
\text { Distant }\end{array}$ & $\begin{array}{l}33.3 \\
66.7\end{array}$ \\
\hline & G2 & $\begin{array}{l}\text { Local (vaginal vault) } \\
\text { Distant }\end{array}$ & $\begin{array}{l}12.0 \\
88.0\end{array}$ \\
\hline & G3 & $\begin{array}{l}\text { Local (vaginal vault) } \\
\text { Distant }\end{array}$ & $\begin{array}{l}0.0 \\
100.0\end{array}$ \\
\hline
\end{tabular}

The analysis of early EC treatment efficiency provided in this paper revealed $23 \%$ recurrence rate. This is not consistent with the outcome of other authors $[12,13]$. The higher cancer stage and/or grade were, the higher risk of either local recurrence or distant metastases was.

Our group of patients was not homogeneous in terms of clinical stage of disease, grade and applied treatment. The patients were initially qualified for the surgical treatment and operated on at different centers. This further enhanced intergroup diversity.

The analyzed cohort revealed high recurrence rate in the patients at stage IA G1 (Tab. 8). This group of patients should have had a good prognosis. Thus, if none risk fac-
Table 7. Metastases (localization and rate) in group of early EC patients. who did not receive any adjuvant treatment

\begin{tabular}{|c|c|c|c|}
\hline \multirow{2}{*}{ Stage } & \multirow{2}{*}{ Grade } & \multicolumn{2}{|l|}{ Metastases } \\
\hline & & Lokalization & Rate [\%] \\
\hline \multirow{3}{*}{ IA } & G1 & $\begin{array}{l}\text { Local (vaginal vault) } \\
\text { Distant }\end{array}$ & $\begin{array}{l}58 \\
42\end{array}$ \\
\hline & G2 & $\begin{array}{l}\text { Local (vaginal vault) } \\
\text { Distant }\end{array}$ & $\begin{array}{l}60 \\
40\end{array}$ \\
\hline & G3 & $\begin{array}{l}\text { Local (vaginal vault) } \\
\text { Distant }\end{array}$ & - \\
\hline \multirow{3}{*}{ IB } & G1 & $\begin{array}{l}\text { Local (vaginal vault) } \\
\text { Distant }\end{array}$ & - \\
\hline & G2 & $\begin{array}{l}\text { Local (vaginal vault) } \\
\text { Distant }\end{array}$ & $\begin{array}{l}100 \\
0\end{array}$ \\
\hline & G3 & $\begin{array}{l}\text { Local (vaginal vault) } \\
\text { Distant }\end{array}$ & $\begin{array}{l}- \\
-\end{array}$ \\
\hline \multirow{3}{*}{ II } & G1 & $\begin{array}{l}\text { Local (vaginal vault) } \\
\text { Distant }\end{array}$ & $\begin{array}{l}100 \\
0\end{array}$ \\
\hline & G2 & $\begin{array}{l}\text { Local (vaginal vault) } \\
\text { Distant }\end{array}$ & $\begin{array}{l}- \\
-\end{array}$ \\
\hline & G3 & $\begin{array}{l}\text { Local (vaginal vault) } \\
\text { Distant }\end{array}$ & - \\
\hline
\end{tabular}

tors for recurrence were present, follow-up after surgery was a recommended procedure. Adjuvant treatment is not recommended, unless any risk factor for recurrence is detected in individual cases. In 2009 FIGO staging system for endometrial cancer changed. The modification shifted patients with former FIGO stage IB (defined as cancer infiltration into myometrium no more than halfway through uterine wall) to the stage IA. Since the new definition of FIGO stage IA had been established, there were two different groups of patients, i.e. the patients with EC limited to the endometrium (with no cancer invasion through basement membrane) and patients with superficial myometrial invasion (less than $50 \%$ of the uterine wall). This means that the patients previously treated with VBT, are now disqualified from any adjuvant treatment (if other risk factors are absent). In our analysis, adjuvant brachytherapy applied in this group (FIGO IA G1) significantly reduced the risk of EC recurrence $(p=0.0006)$ (Tab. 2). Similar results were provided by other authors [8, 14-17].

Our analysis also revealed high recurrence rate in the group of patients at FIGO stage II. This means that patients who underwent a complete radical radiation therapy are still at high risk of recurrence. This in turn may suggest that the disease at the time of therapy planning was more advanced than the diagnosis based on histopathological report stated.

One of the most important topics is quality and accuracy of the histopathological report. Boer at al. re-evaluated histopathological reports of the patients included into PORTEC-3 study in England and Norway [18]. The re-evaluation 


\begin{tabular}{|c|c|c|c|c|c|c|c|}
\hline \multirow[b]{2}{*}{ Stage } & \multirow[b]{2}{*}{ Grade } & \multicolumn{3}{|c|}{ Adjuvant treatment } & \multicolumn{3}{|l|}{ Recurrence } \\
\hline & & Altogether & Yes & No & Altogether & Adjuvant treatment & No adjuvant treatment \\
\hline \multirow{3}{*}{ IA } & G1 & 53 & 16 & 37 & 20 & 1 & 19 \\
\hline & G2 & 47 & 40 & 7 & 11 & 7 & 4 \\
\hline & G3 & 12 & 11 & 1 & 1 & 1 & 0 \\
\hline \multirow{3}{*}{ I B } & G1 & 69 & 68 & 1 & 9 & 8 & 1 \\
\hline & G2 & 116 & 115 & 1 & 21 & 20 & 1 \\
\hline & G3 & 31 & 31 & 0 & 8 & 8 & 0 \\
\hline \multirow{3}{*}{ II } & G1 & 30 & 29 & 1 & 11 & 10 & 1 \\
\hline & G2 & 51 & 51 & 0 & 25 & 25 & 0 \\
\hline & G3 & 10 & 10 & 0 & 2 & 2 & 0 \\
\hline
\end{tabular}

revealed modification of at least one assessed factor in $43 \%$ of cases. In $34 \%$ of cases the type of malignancy changed, in $27 \%$ the depth of infiltration, and in $19 \%$ the cancer grade [18]. These modifications considerably altered indications for adjuvant treatment, and demonstrated that the patients should have been qualified for this type of therapy [19-23].

The discussed discrepancies in treatment results might be caused by differences in surgical procedures and specimen preparation at different centers and pathology departments (differences in laboratory protocols of specimen preparation). Those differences affected accuracy of the final pathological reports, as described and analyzed by Mitchard and Hirschowitz [24, 25].

The final parameter to be discussed is positive LVSI. Recent studies implied that positive LVSI at early stages of EC is sufficient to recommend a more aggressive treatment, especially in cases of coexisting risk factors. Bosse et al. re-evaluated histopathological data of the patients included into PORTEC-1 and PORTEC-2 study [18]. They found out that positive LVSI was an independent negative prognostic factor for local recurrence, distant metastases and overall survival [26]. They also concluded that histopathological examinations should be performed at referential centers [27-33].

For a long time, European scientific organizations engaged in EC treatment would not agree on the guidelines on EC management. In 2016, European Society of Gynecological Oncology (ESGO), European Society for Radiotherapy and Oncology (ESTRO) and European Society of Medical Oncology (ESMO) finally published a consensus outlining diagnostics, qualification for treatment and extent of surgery at specific stages of the disease. They also provided detailed guidelines for adjuvant treatment and post treatment follow up. There is still place for immune therapy and targeted therapy in EC that will hopefully have positive impact on PFS and OS [34, 35].
The next step should be an evaluation of patients treated for recurrence that were exposed to radiation and/or chemotherapy.

\section{CONCLUSIONS}

Early EC treatment outcomes were unsatisfactory and should be improved. High rate of recurrence in early endometrial cancer reported recently encouraged us to investigate the factors responsible for the treatment failure. In patients at IA G1 stage brachytherapy seems justified even though studies suggest only careful followup. Brachytherapy introduced in the analyzed group significantly reduced local recurrence.

In patients at this stage, the adjuvant treatment (vaginal brachytherapy alone) seemed reasonable. The women who underwent this treatment scored better than those who did not receive any adjuvant therapy, and we concluded that vaginal brachytherapy dramatically improved locoregional control of the disease.

\section{REFERENCES}

1. International Agency for Research on Cancer (IARC). The Grants Register 2018. 2018: 412-413, doi: 10.1007/978-1-349-94186-5 629.

2. Wojciechowska U, Didkowska J, Zatoński W. Nowotwory złośliwe w Polsce w 2008 roku. Centrum Onkologii. Instytut im. M. SkłodowskiejCurie, Warszawa : 38-39.

3. Yang HP, Cook LS, Weiderpass E, et al. Infertility and incident endometrial cancer risk: a pooled analysis from the epidemiology of endometrial cancer consortium (E2C2). Br J Cancer. 2015; 112(5): 925-933, doi: 10.1038/bjc.2015.24, indexed in Pubmed: 25688738.

4. TurklerC, Kulhan M, Kulhan N, et al. Role of lymphadenectomy in disease-free and overall survival on low risk endometrium cancer patients. Ginekologia Polska. 2018; 89(6): 311-315, doi: 10.5603/gp.a2018.0053.

5. NCCN Clinical Practice Guidelines, Uterin Cancer. http://nccn.com.

6. de Boer SM, Nout RA, Jürgenliemk-Schulz IM, et al. PORTEC Study Group. Quality of life after pelvic radiotherapy or vaginal brachytherapy for endometrial cancer: first results of the randomized PORTEC- 2 trial. J Clin Oncol. 2009; 27(21): 3547-3556, doi: 10.1200/JCO.2008.20.2424, indexed in Pubmed: 19546404.

7. Wareńczak-Florczak Ż, Roszak A, Włodarczyk H, et al. Analysis of acute and late toxicity of adjuvant radiotherpy in women with cervical and 
endometrial cancer. Współczesna Onkologia. 2011; 1: 15-19, doi: 10.5114/wo.2011.20526.

8. Creutzberg CL, van Putten WL, Koper PC, et al. Surgery and postoperative radiotherapy versus surgery alone for patients with stage- 1 endometrial carcinoma: multicentre randomised trial. PORTEC Study Group. Post Operative Radiation Therapy in Endometrial Carcinoma. Lancet. 2000; 355(9213): 1404-1411, doi: 10.1016/s0140-6736(00)02139-5, indexed in Pubmed: 10791524.

9. Colombo N, Creutzberg C, Amant F, et al. ESMO-ESGO-ESTRO Endometrial Consensus Conference Working Group. ESMO-ESGO-ESTRO Consensus Conference on Endometrial Cancer: Diagnosis, Treatment and Follow-up. Int J Gynecol Cancer. 2016; 26(1): 2-30, doi: 10.1097/IGC.0000000000000609, indexed in Pubmed: 26645990.

10. Jutzi L, Hoskins P, Lim P, et al. The importance of adjuvant chemotherapy and pelvic radiotherapy in high-risk early stage endometrial carcinoma. Gynecol Oncol. 2013; 131(3): 581-585, doi: 10.1016/j.ygyno.2013.09.012, indexed in Pubmed: 24055614.

11. Maggi R, Lissoni A, Spina F, et al. Adjuvant chemotherapy vs radiotherapy in high-risk endometrial carcinoma: results of a randomised trial. $\mathrm{Br}$ J Cancer. 2006; 95(3): 266-271, doi: 10.1038/sj.bjc.6603279, indexed in Pubmed: 16868539.

12. Adjuvant external beam radiotherapy in the treatment of endometrial cancer (MRC ASTEC and NCIC CTG EN.5 randomised trials): pooled trial results, systematic review, and meta-analysis. The Lancet. 2009; 373(9658): 137-146, doi: 10.1016/s0140-6736(08)61767-5.

13. Keys HM, Roberts JA, Brunetto VL, et al. Gynecologic Oncology Group. A phase III trial of surgery with or without adjunctive external pelvic radiation therapy in intermediate risk endometrial adenocarcinoma: a Gynecologic Oncology Group study. Gynecol Oncol. 2004; 92(3): 744751, doi: 10.1016/j.ygyno.2003.11.048, indexed in Pubmed: 14984936.

14. Dohopolski MJ, Horne ZD, Gebhardt BJ, et al. Single-institutional outcomes of adjuvant brachytherapy for Stage I endometrial cancer-Are outcomes consistent with randomized studies? Brachytherapy. 2018; 17(3): 564-570, doi: 10.1016/j.brachy.2018.01.004, indexed in Pubmed: 29426745.

15. Harkenrider MM, Block AM, Siddiqui ZA, et al. The role of vaginal cuff brachytherapy in endometrial cancer. Gynecol Oncol. 2015; 136(2): 365372, doi: 10.1016/j.ygyno.2014.12.036, indexed in Pubmed: 25555710.

16. Harkenrider MM, Block AM, Alektiar KM, et al. American Brachytherapy Task Group Report: Adjuvant vaginal brachytherapy for early-stage endometrial cancer: A comprehensive review. Brachytherapy. 2017; 16(1): 95-108, doi: 10.1016/j.brachy.2016.04.005, indexed in Pubmed: 27260082.

17. Kumar VJ, Nin CY, Kuei LY, et al. Survival and disease relapse in surgical stage I endometrioid adenocarcinoma of the uterus after adjuvant vaginal vault brachytherapy. Int J Gynecol Cancer. 2010; 20(4): 564-569, doi: 10.1111/IGC.0b013e3181d7ce94, indexed in Pubmed: 20686374.

18. Boer SMde, Wortman BG, Bosse T, et al. Clinical consequences of upfront pathology review in the randomised PORTEC-3 trial for high-risk endometrial cancer. Annals of Oncology. 2017; 29(2): 424-430, doi: 10.1093/annonc/mdx753.

19. Cwonda $Ł$, Wójcik-Krowiranda K, Michalski T, et al. Analysis of pre- and postoperative pathological findings in endometrial cancer. Current Gynecologic Oncology. 2017; 15(2): 105-112, doi: 10.15557/cgo.2017.0010.

20. Kisielewski F, Gajewska ME, Marczewska MJ, et al. Comparison of endometrial biopsy and postoperative hysterectomy specimen findings in patients with atypical endometrial hyperplasia and endometrial cancer. Ginekol Pol. 2016; 87(7): 488-492, doi: 10.5603/GP.2016.0031, indexed in Pubmed: 27504940.
21. Vorgias G, Lekka J, Katsoulis M, et al. Diagnostic accuracy of prehysterectomy curettage in determining tumor type and grade in patients with endometrial cancer. MedGenMed. 2003; 5(4): 7, indexed in Pubmed: 14745354.

22. Barut A, Barut F, Arikan I, et al. Comparison of the histopathological diagnoses of preoperative dilatation and curettage and hysterectomy specimens. J Obstet Gynaecol Res. 2012; 38(1): 16-22, doi: 10.1111/j.14 47-0756.2011.01633.x, indexed in Pubmed: 21917068.

23. Sany O, Singh K, Jha S. Correlation between preoperative endometrial sampling and final endometrial cancer histology. Eur J Gynaecol Oncol. 2012; 33(2): 142-144, indexed in Pubmed: 22611951.

24. Mitchard J, Hirschowitz L. Concordance of FIGO grade of endometrial adenocarcinomas in biopsy and hysterectomy specimens. Histopathology. 2003; 42(4): 372-378, doi: 10.1046/j.1365-2559.2003.01603.x, indexed in Pubmed: 12653949.

25. Taoussi N, Alghamdi A, Futyma K, et al. Biological markers with potential clinical value in endometrial cancer - review of the literature. Ginekologia Polska. 2017; 88(6): 331-336, doi: 10.5603/gp.a2017.0062.

26. Bosse T, Peters EEM, Creutzberg CL, et al. Substantial lymph-vascular space invasion (LVSI) is a significant risk factor for recurrence in endometrial cancer--A pooled analysis of PORTEC 1 and 2 trials. Eur J Cancer. 2015; 51(13): 1742-1750, doi: 10.1016/j.ejca.2015.05.015, indexed in Pubmed: 26049688.

27. Lee S, Park JW, Han M, et al. Lymphovascular space invasion, a prognostic marker for disease recurrence in patients with early endometrioid endometrial cancer. Current Gynecologic Oncology. 2017; 15(3): 183-188, doi: $10.15557 /$ cgo.2017.0018.

28. Nofech-Mozes S, Ackerman I, Ghorab Z, et al. Lymphovascular invasion is a significant predictor for distant recurrence in patients with early-stage endometrial endometrioid adenocarcinoma. Am J Clin Pathol. 2008; 129(6): 912-917, doi: 10.1309/CP3HGX7H753QQU8T, indexed in Pubmed: 18480008.

29. Ayhan $A$, Tuncer $Z S$, Tuncer $R$, et al. Risk factors for recurrence in clinically early endometrial carcinoma: an analysis of 183 consecutive cases. Eur J Obstet Gynecol Reprod Biol. 1994; 57(3): 167-170, doi: 10.1016/00282243(94)90294-1, indexed in Pubmed: 7713290.

30. Cohn DE, Horowitz NS, Mutch DG, et al. Should the presence of lymphvascular space involvement be used to assign patients to adjuvant therapy following hysterectomy for unstaged endometrial cancer? Gynecol Oncol. 2002; 87(3): 243-246, doi: 10.1006/gyno.2002.6825, indexed in Pubmed: 12468320.

31. Guntupalli SR, Zighelboim I, Kizer NT, et al. Lymphovascular space invasion is an independent risk factor for nodal disease and poor outcomes in endometrioid endometrial cancer. Gynecol Oncol. 2012; 124(1): 31-35, doi: 10.1016/j.ygyno.2011.09.017, indexed in Pubmed: 22030404.

32. Briët JM, Hollema $\mathrm{H}$, Reesink $\mathrm{N}$, et al. Lymphvascular space involvement: an independent prognostic factor in endometrial cancer. Gynecol Oncol. 2005; 96(3): 799-804, doi: 10.1016/j.ygyno.2004.11.033, indexed in Pubmed: 15721428

33. Gemer $\mathrm{O}$, Arie $\mathrm{AB}$, Levy $\mathrm{T}$, et al. Lymphvascular space involvement compromises the survival of patients with stage I endometrial cancer: results of a multicenter study. Eur J Surg Oncol. 2007; 33(5): 644-647, doi: 10.1016/j.ejso.2007.01.009, indexed in Pubmed: 17317084.

34. Hecht JL, Mutter GL. Molecular and pathologic aspects of endometrial carcinogenesis. J Clin Oncol. 2006; 24(29): 4783-4791, doi: 10.1200/JCO.2006.06.7173, indexed in Pubmed: 17028294.

35. Karnezis AN, Leung S, Magrill J. Evaluation of endometria carcinoma prognostic immunohistochemistry markers In the context of molecular classification, J Path. Clin Res. ; 3: 279-293. 